\title{
Lipoprotein Abnormalities in Patients with Atherosclerotic Renovascular Disease
}

\author{
Elzbieta Nowakowska Fortuna ${ }^{a}$ Hans Herlitz $^{\text {a }}$ Aso Saeed $^{\text {a }}$ Per-Ola Attman ${ }^{a}$ \\ Gert Jensen $^{\mathrm{a}}$ Petar Alaupovic $^{\mathrm{b}}$ Gregor Guron ${ }^{\mathrm{a}}$ \\ ${ }^{a}$ Department of Molecular and Clinical Medicine/Nephrology, Institute of Medicine, The Sahlgrenska Academy

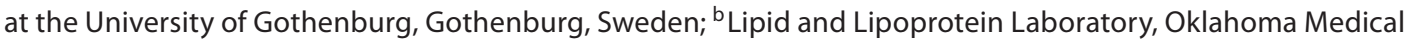 \\ Research Foundation, Oklahoma City, Okla., USA
}

\section{Key Words}

Apolipoprotein C-III - Atherosclerosis · Chronic kidney

disease $\cdot$ Dyslipidemia $\cdot$ Renal artery stenosis •

Renovascular disease

\begin{abstract}
Background: Patients with atherosclerotic renovascular disease (ARVD) have a high risk of cardiovascular death. The primary aim was to characterize abnormalities in apolipoprotein (Apo)-defined lipoprotein (Lp) subclasses in patients with ARVD. Methods: Baseline measurements were performed on 42 patients with ARVD 4 weeks after renal angioplasty (PTRA). All patients were on statin treatment. Twenty age-matched healthy subjects without medications served as controls. Subsequently, patients were randomized to treatment with either candesartan $(n=21)$, or antihypertensive treatment without inhibitors of the renin-angiotensinaldosterone system $(n=21)$ and followed for 11 months. $R \boldsymbol{e}$ sults: At baseline, ApoC-III (12.7 \pm 4.6 vs. $8.8 \pm 2.6$ (SD) mg/ $\mathrm{dl}, \mathrm{p}<0.05), \mathrm{LpB}: \mathrm{C}: \mathrm{E}(13.3 \pm 5.4 \mathrm{vs} .8 .4 \pm 4.3 \mathrm{mg} / \mathrm{dl}, \mathrm{p}<0.05)$, and the sum of ApoC-IIl-containing lipoproteins, i.e. LpB:C + LpB:C:E + LpA-Il:B:C:D:E (46 \pm 15 vs. $37 \pm 8$ mg/dl, p<0.05), were significantly elevated in ARVD patients versus healthy controls. Multiple regression analyses showed that only plasma renin activity was independently associated with ApoC-
\end{abstract}

\section{KARGER}

Fax +41613061234 E-Mail karger@karger.ch www.karger.com

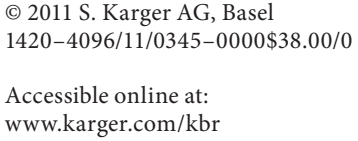

III levels at baseline $(p<0.05, r=0.74)$. Treatment with candesartan did not correct abnormalities. Conclusions: Patients with ARVD treated with statins have an atherogenic lipoprotein profile characterized by elevated levels of ApoCIII-containing, triglyceride-rich lipoproteins that could accelerate atherosclerotic disease.

Copyright $\odot 2011$ S. Karger AG, Basel

\section{Introduction}

Renal artery stenosis (RAS) is mainly caused by atherosclerosis, and cardiovascular (CV) mortality in patients with atherosclerotic RAS (ARAS) is high $[1,2]$. In addition, the presence of RAS is a strong independent predictor of mortality, and increasing severity of RAS has an incremental effect on mortality in patients undergoing coronary angiography [3]. The reason for the increased $\mathrm{CV}$ mortality in this patient group is most likely multifactorial and may at least partially be a consequence of the generalized atherosclerotic burden. Still, other risk factors such as reduced glomerular filtration rate (GFR) [1] and dyslipidemia [4] may also be involved. In patients with atherosclerotic renovascular disease (ARVD), dyslipidemia could obviously be a primary event leading to the development of peripheral stenotic lesions involving 
renal arteries. However, dyslipidemia can also develop as a consequence of reduced GFR (i.e. renal dyslipidemia) [5] and may thus be superimposed on primary ARVD. Notably, renal dyslipidemia is not always reflected in hyperlipidemia but in altered concentrations of individual lipoprotein subclasses classified according to their apolipoprotein (Apo) composition [6-8]. Renal dyslipidemia is characterized by the accumulation of atherogenic ApoB- and ApoC-containing lipoproteins $[7,8]$ and could hence add to pre-existing perturbations of lipoprotein metabolism. The classification system of lipoproteins recognizes two classes, one of which is characterized by ApoA and the other by ApoB as the major lipoprotein constituents. The former lipoprotein class consists of two major lipoprotein subclasses, lipoprotein A-I (LpAI) and lipoprotein A-I:A-II (LpA-I:A-II), whereas the latter encompasses five major subclasses called lipoprotein B (LpB), lipoprotein B:E (LpB:E), lipoprotein B:C (LpB:C), lipoprotein B:C:E (LpB:C:E), and lipoprotein A-II:B:C:D:E (LpAII:B:C:D:E) [6, 9]. In addition to their unique apolipoprotein composition, each of these lipoprotein subclasses has specific metabolic and functional properties $[6,9]$. Furthermore, previous studies have indicated that ApoB-containing lipoprotein subclasses may differ in their atherogenic capacities $[6,10,11]$ and ApoA-containing lipoproteins in their antiatherogenic potentials $[6$, 12-14]. While lipoprotein subclasses have been analyzed in detail in patients with chronic kidney disease (CKD) $[7,8,15,16]$, such analyses have to our knowledge not been carried out in patients with ARVD.

The primary aim of the present study was to characterize abnormalities in apolipoprotein-defined lipoprotein subclasses in patients with ARVD who had undergone percutaneous transluminal renal angioplasty (PTRA) 4 weeks earlier. We hypothesized that ARVD patients could have a particularly atherogenic lipoprotein profile that could contribute to accelerated $\mathrm{CV}$ disease. In addition, to examine the potential role of the renin-angiotensin system in lipoprotein abnormalities, we analyzed whether antihypertensive treatment with the angiotensin II (Ang II) receptor antagonist candesartan influenced lipoproteins during an 11-month follow-up.

\section{Subjects and Methods}

\section{Study Participants}

Patients were recruited from the (CAndesartan in RenaL Artery Stenosis) study program, a randomized, open, investigatorinitiated trial in which the effects of the Ang II receptor blocker (ARB) candesartan was examined in patients with ARVD who had undergone treatment with PTRA with or without stenting. This study was carried out at two Swedish centers (Department of Nephrology at Sahlgrenska University Hospital in Gothenburg, and Department of Vascular Diseases at Malmö University Hospital) and has been described previously, and the inclusion and exclusion criteria have also been presented [17]. In brief, indications for renal angiography were hypertension (accelerated, refractory, malignant or with intolerance to medication) or progressive increase in plasma creatinine concentrations (unexplained or during treatment with an angiotensin-converting enzyme (ACE) inhibitor or an ARB), or recurrent hypertensive pulmonary edema, together with a positive screening test for RAS. A significant RAS was defined as a lesion with a trans-stenotic mean arterial pressure gradient (MAPG) of at least $10 \mathrm{~mm} \mathrm{Hg}$, or $>50 \%$ diameter stenosis on angiography in those cases in which the MAPG was not measured because of technical difficulties due to highgrade stenosis and luminal occlusion during the procedure. The procedures of renal angiography and PTRA have been described previously [17].

In the CARLAS study, eligible patients with remaining hypertension (trough $\mathrm{BP}>130 / 80 \mathrm{~mm} \mathrm{Hg}$ ) 4 weeks after PTRA, underwent simple randomization $(\mathrm{n}=64)$, in an open fashion, to antihypertensive treatments based on either candesartan (ARVD-CAN group) or a regimen without inhibitors of the renin-angiotensin-aldosterone system, i.e. ACE inhibitors, ARBs, renin inhibitors or aldosterone receptor antagonists (ARVD-C (control) group). The randomization procedure was carried out by the use of sequentially numbered, opaque, sealed envelopes. The targeted candesartan dose was $16 \mathrm{mg}$ daily and the trough BP goal was $\leq 130 / 80 \mathrm{~mm} \mathrm{Hg}$. All patients had discontinued treatment with inhibitors of the renin-angiotensin-aldosterone system at least 6 weeks prior to randomization, i.e. 2 weeks before PTRA. In addition, all patients had been on treatment with hydroxymethylglutaryl coenzyme A (HMG-CoA) reductase inhibitors (i.e. statins) for at least 6 weeks prior to randomization and this treatment was maintained throughout the study period. The Ethics Committees of the Universities of Gothenburg and Lund approved the study and all participants gave their written consent to participate.

\section{Protocol}

We investigated lipid abnormalities in a subgroup of 42 ARVD patients from the CARLAS study program at the time of randomization (baseline) 4 weeks after PTRA (see fig. 1 for protocol overview). These patients were selected as they were the only participants with a sufficient amount of appropriately collected and stored plasma for lipid analyses (see 'Biochemical Analyses'). All patients were from the center at Sahlgrenska University Hospital in Gothenburg. At 6 weeks prior to randomization, 20 patients were already on treatment with statins and continued with the same drug and dose throughout. In the remaining 22 patients, treatment with simvastatin was started at this time point with a daily dose of $20 \mathrm{mg}$ that was maintained throughout. At randomization, 29 patients used simvastatin (average daily dose $19 \mathrm{mg}$ ), 8 used pravastatin (average daily dose $30 \mathrm{mg}$ ) and 5 used atorvastatin (average daily dose $42 \mathrm{mg}$ ). No patient was treated with lipid-lowering drugs other than statins. In addition, 20 age-matched healthy subjects from the general population without any medications were examined at one time point and served as controls.
Nowakowska Fortuna/Herlitz/Saeed/ Attman/Jensen/Alaupovic/Guron 
Following randomization to group ARVD-CAN $(\mathrm{n}=21)$ or group ARVD-C $(n=21)$, the patients were followed for 11 months at which time point new lipid analyses were carried out (fig. 1). Lipid analyses were only performed in 32 of 42 patients at 11 months (16 patients from each group) due to 3 deaths, 2 individuals ended their participation, and in 5 patients there was an insufficient amount of plasma. Hence, when examining the effects of randomization, analyses were performed on 16 patients per group.

\section{Measurements}

Systolic (SBP) and diastolic (DBP) blood pressure (BP) were measured in a sitting position after $5 \mathrm{~min}$ rest in the morning before drug intake. Ambulatory (24 h) SBP (ASBP) and DBP (ADBP) were measured by an ambulatory BP system (Model 90217, Spacelabs Healthcare). Estimated glomerular filtration rate (eGFR) was calculated according to the 4 -variable equation from the Modification of Diet in Renal Disease (MDRD) study [18].

\section{Biochemical Analyses}

Standard laboratory methods at the Department of Clinical Chemistry at Sahlgrenska University Hospitals (SWEDAC approved according to European norm 45001) were used for routine analyses. Plasma renin activity (PRA) was determined by radioimmunoassay (Abbot Diagnostics, South Pasadena, Calif., USA), the interassay coefficient of variation was $8.8 \%$.

Venous blood for analyses of lipids, lipoproteins and apolipoproteins was collected into ethylenediaminetetraacetate-containing vacutainer tubes after an overnight fast and with individuals in the recumbent position. Plasma samples were recovered by low-speed centrifugation for $10 \mathrm{~min}$ at $4{ }^{\circ} \mathrm{C}$. A preservative solution $(0.13 \%$ e-aminocaproic acid and $0.1 \%$ thiomerosal) was added $(10 \mu \mathrm{l} / \mathrm{ml})$ to all plasma samples and samples were frozen at $-70^{\circ} \mathrm{C}$ until shipped on dry ice by air express mail to the Lipid and Lipoprotein Laboratory, Oklahoma Medical Research Foundation for analyses. Total cholesterol (TC), triglycerides (TG), and HDL-cholesterol (HDL-C) were determined by standardized enzymatic procedures as described previously [19]. Very-low-density lipoprotein cholesterol (VLDL-C) was assumed to equal onefifth of the plasma TG concentration, and LDL cholesterol (LDLC) levels were calculated by the procedure of Friedewald et al. [20]. Measurements of ApoA-I, ApoB, ApoC-III and ApoE and the quantification of ApoC-III bound to ApoA-containing (HDL) and ApoB-containing (VLDL + LDL) lipoproteins, performed on heparin $\mathrm{Mn}^{2+}$ supernates (ApoC-III heparin manganese supernate) and heparin $\mathrm{Mn}^{2+}$ precipitates (ApoC-III-heparin manganese precipitate), were carried out as described previously $[9,19]$.

Plasma concentrations of LpA-I and LpA-I:A-II subclasses of high-density properties were determined by a differential electroimmunoassay [21]. Determination of plasma levels of individual ApoB-containing lipoprotein subclasses, LpB, LpB:C, LpB:C:E, and LpAII:B:C:D:E, was performed by sequential immunoaffinity chromatography of ApoB-containing lipoproteins as previously described [22]. Methods for analyses of plasma lipids, apolipoproteins and lipoprotein subclasses have been described elsewhere in detail $[9,22,23]$.

\section{Statistics}

Differences between groups were evaluated with the MannWhitney $U$ test and the $\chi^{2}$ test. The Wilcoxon signed-rank test was used for within-group analyses. Multiple linear regression

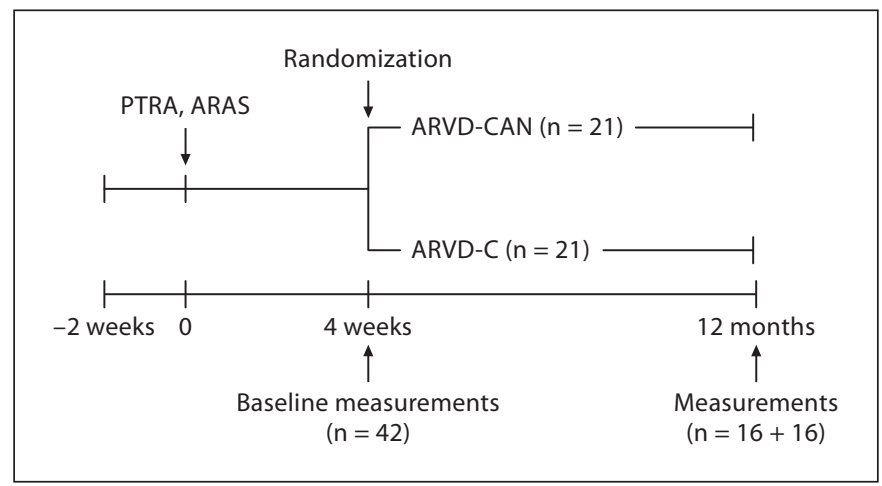

Fig. 1. Study protocol. Patients with ARVD $(n=42)$ were subjected to baseline measurements at the time of randomization 4 weeks after PTRA. Following randomization to treatments based on either candesartan (ARVD-CAN group, $n=21$ ), or a treatment regimen without inhibitors of the renin-angiotensin-aldosterone system (ARVD-C group, $\mathrm{n}=21$ ), patients were followed for 11 months at which time point new analyses were carried out. However, measurements were only performed on 32 patients at 11 months (16 patients per group, see 'Subjects and Methods'). In all patients, treatment with inhibitors of the renin-angiotensin-aldosterone system was discontinued 2 weeks before renal angiography, i.e. 6 weeks prior to randomization. At this time point all participants who were already not on statins started treatment with simvastatin (see 'Subjects and Methods').

analysis was used to examine the association at baseline between apolipoproteins or lipoproteins and demographic, clinical and laboratory variables. Variables that were significantly correlated were included in multiple regression models and analyzed by ANOVA. All tests were two-tailed and $\mathrm{p}<0.05$ was considered significant. Data are presented as means \pm SD. Software SPSS 17.0 (SPSS Inc., Chicago, Ill., USA) was used.

\section{Results}

\section{Patient Characteristics at Baseline, ARVD versus Healthy Controls}

Baseline characteristics in patients with ARVD 4 weeks after PTRA and in healthy controls are shown in table 1. Ambulatory SBP and DBP, serum creatinine concentrations, leukocyte count, fasting plasma glucose concentrations, and urinary albumin excretion (UAE) were significantly elevated in patients with ARVD compared to controls ( $p<0.05$; table 1$)$. In addition, eGFR was significantly reduced in ARVD patients compared to controls ( $\mathrm{p}<0.05$; table 1). Four of 42 ARVD patients had a diagnosis of type 2 diabetes. Still, fasting plasma glucose levels were significantly elevated in ARVD patients even 
Table 1. Baseline characteristics in patients with ARVD 4 weeks after renal angioplasty and in age-matched healthy controls

\begin{tabular}{lcc}
\hline & $\begin{array}{c}\text { ARVD } \\
(\mathrm{n}=42)\end{array}$ & $\begin{array}{c}\text { Controls } \\
(\mathrm{n}=20)\end{array}$ \\
\hline Age, years & $64 \pm 8$ & $63 \pm 11$ \\
Sex, male/female & $28 / 14$ & $9 / 11$ \\
BMI & $26.7 \pm 3.5$ & $25.9 \pm 3.4$ \\
Smokers, $\mathrm{n}$ & $11 / 42$ & $2 / 20$ \\
Diabetes mellitus, $\mathrm{n}$ & $4 / 42$ & $0 / 20$ \\
ASBP, $\mathrm{mm} \mathrm{Hg}$ & $139 \pm 15^{*}$ & $115 \pm 9$ \\
ADBP, mm Hg & $78 \pm 11^{*}$ & $71 \pm 6$ \\
S-creatinine, $\mu \mathrm{mol} / \mathrm{l}$ & $110 \pm 37^{*}$ & $77 \pm 14$ \\
eGFR, ml/min/1.73 m ${ }^{2}$ & $59 \pm 18^{*}$ & $79 \pm 14$ \\
PRA, ng Ang I/ml/h & $1.90 \pm 2.26$ & $1.23 \pm 0.65$ \\
Leukocyte count, $10^{9} / \mathrm{l}$ & $7.8 \pm 1.9^{*}$ & $6.3 \pm 2.0$ \\
Fasting P-glucose, $\mathrm{mmol} / \mathrm{l}$ & $5.7 \pm 1.4^{*}$ & $4.6 \pm 0.8$ \\
Urinary albumin excretion, mg/day & $140 \pm 285^{*}$ & $7 \pm 4$ \\
\hline
\end{tabular}

$\mathrm{BMI}=$ Body mass index; ASBP = ambulatory systolic blood pressure during $24 \mathrm{~h}$; ADBP = ambulatory diastolic blood pressure during $24 \mathrm{~h}$; eGFR = estimated glomerular filtration rate; $\mathrm{PRA}=$ plasma renin activity. Values are means $\pm \mathrm{SD} .{ }^{*} \mathrm{p}<0.05$.

when patients with type 2 diabetes were excluded from the analyses $(5.5 \pm 1.1$ vs. $4.6 \pm 0.8 \mathrm{mmol} / \mathrm{l}, \mathrm{p}<0.05)$. The median value in UAE in ARVD patients was $18 \mathrm{mg} /$ day and the maximal value was $1,485 \mathrm{mg} /$ day. There were no significant differences between groups in age, BMI or PRA (table 1). All patients with ARVD were investigated with color duplex sonography 4 weeks after PTRA and none of the patients showed signs of restenosis.

\section{Plasma Lipids, Apolipoproteins and Lipoproteins at}

Baseline, ARVD versus Healthy Controls

Patients with ARVD had reduced levels of TC, LDL-C and HDL-C compared to healthy controls, whereas VLDL-C and TG were elevated ( $\mathrm{p}<0.05$; table 2 ).

Patients with ARVD had significantly increased plasma concentrations of ApoC-III, ApoC-III-HS and ApoCIII-HP compared to healthy controls $(\mathrm{p}<0.05)$, whereas the ratio between ApoC-III-HS and ApoC-III-HP was not significantly altered (table 3). Similarly, plasma ApoE levels were elevated in ARVD patients ( $p<0.05$; table 3$)$. There was no statistically significant difference between groups in ApoA-I and ApoB plasma concentrations or in the ApoB/ApoA-I ratio (table 3). The ratio between ApoAI and ApoC-III was clearly reduced in patients with ARVD compared to in healthy individuals $(\mathrm{p}<0.05$; table 3).
Table 2. Lipids and lipoproteins at baseline in patients with ARVD treated with statins, and in age-matched healthy controls

\begin{tabular}{lcc}
\hline & ARVD $(\mathrm{n}=42)$ & Controls $(\mathrm{n}=20)$ \\
\hline TC, mg/dl & $177 \pm 36^{*}$ & $217 \pm 36$ \\
HDL-C, mg/dl & $49 \pm 13^{*}$ & $65 \pm 14$ \\
LDL-C, mg/dl & $96 \pm 28^{*}$ & $130 \pm 38$ \\
VLDL-C, mg/dl & $32 \pm 14^{*}$ & $23 \pm 10$ \\
TG, mg/dl & $166 \pm 88^{*}$ & $116 \pm 49$ \\
\hline
\end{tabular}

$\mathrm{TC}=$ Total cholesterol; HDL-C = high-density lipoproteincholesterol; LDL-C = low-density lipoprotein-cholesterol; VLDL$\mathrm{C}=$ very-low-density lipoprotein-cholesterol; $\mathrm{TG}=$ triglycerides. Values are means \pm SD. ${ }^{*} \mathrm{p}<0.05$.

Table 3. Plasma concentrations of apolipoproteins at baseline in patients with ARVD treated with statins, and in age-matched healthy controls

\begin{tabular}{lcc}
\hline & ARVD $(\mathrm{n}=42)$ & Controls $(\mathrm{n}=20)$ \\
\hline ApoA-I, mg/dl & $141 \pm 13$ & $141 \pm 11$ \\
ApoB, mg/dl & $103 \pm 19$ & $95 \pm 11$ \\
ApoB/ApoA-I & $0.73 \pm 0.13$ & $0.68 \pm 0.10$ \\
ApoC-III, mg/dl & $12.7 \pm 4.6^{*}$ & $8.8 \pm 2.6$ \\
ApoC-III-HS, mg/dl & $8.9 \pm 3.2^{*}$ & $5.3 \pm 1.8$ \\
ApoC-III-HP, mg/dl & $3.9 \pm 1.8^{*}$ & $3.0 \pm 1.2$ \\
ApoC-III ratio & $2.5 \pm 0.9$ & $2.4 \pm 1.6$ \\
ApoA-I/ApoC-III & $12.1 \pm 3.5^{*}$ & $17.2 \pm 4.6$ \\
ApoE, mg/dl & $8.2 \pm 2.3^{*}$ & $6.7 \pm 1.1$ \\
\hline
\end{tabular}

Apo = Apolipoprotein; HS = heparin-manganese supernate; $\mathrm{HP}=$ heparin-manganese precipitate. The ApoC-III ratio was calculated as ApoC-III-HS/ApoC-III-HP. Values are means \pm SD.

${ }^{*} \mathrm{p}<0.05$.

There were no statistically significant differences between groups in ApoA-containing lipoprotein subclasses LpA-I and LpA-I:A-II (table 4). Regarding ApoB-containing lipoprotein subclasses, ARVD patients showed elevated levels of LpB:C:E ( $<$ 0.05) compared to healthy controls (table 4). Levels of LpB:C and LpA-II:B:C:D:E tended to be elevated in ARVD patients but did not reach statistical significance (table 4). However, the sum of all ApoCIII-containing lipoproteins (i.e. LpB:C + LpB:C:E + LpAII:B:C:D:E) was significantly elevated in ARVD patients compared to healthy controls ( $p<0.05$; table 4 ).

To assess the impact of diabetes on lipids, apolipoproteins and lipoproteins, data were also analyzed statisti- 
Table 4. Lipoprotein subclasses at baseline in patients with ARVD treated with statins, and in age-matched healthy controls

\begin{tabular}{lcc}
\hline & $\begin{array}{l}\text { ARVD } \\
(\mathrm{n}=42)\end{array}$ & $\begin{array}{l}\text { Controls } \\
(\mathrm{n}=20)\end{array}$ \\
\hline LpA-I, mg/dl & $35 \pm 4$ & $33 \pm 2$ \\
LpA-I:A-II, mg/dl & $107 \pm 10$ & $108 \pm 9$ \\
LpB, mg/dl & $57.0 \pm 7.8$ & $57.7 \pm 4.5$ \\
LpB:C, mg/dl & $11.1 \pm 4.1$ & $9.5 \pm 4.1$ \\
LpB:C:E, mg/dl & $13.3 \pm 5.4^{*}$ & $8.4 \pm 4.3$ \\
LpA-II:B:C:D:E, mg/dl & $21.4 \pm 8.9$ & $19.2 \pm 7.0$ \\
ApoC-III-containing Lp:s, mg/dl & $46 \pm 15^{*}$ & $37 \pm 8$ \\
\hline
\end{tabular}

ApoC-III-containing Lp:s were calculated as LpB:C + LpB:C:E + LpA-II:B:C:D:E. Values are means \pm SD. ${ }^{*} \mathrm{p}<0.05$.

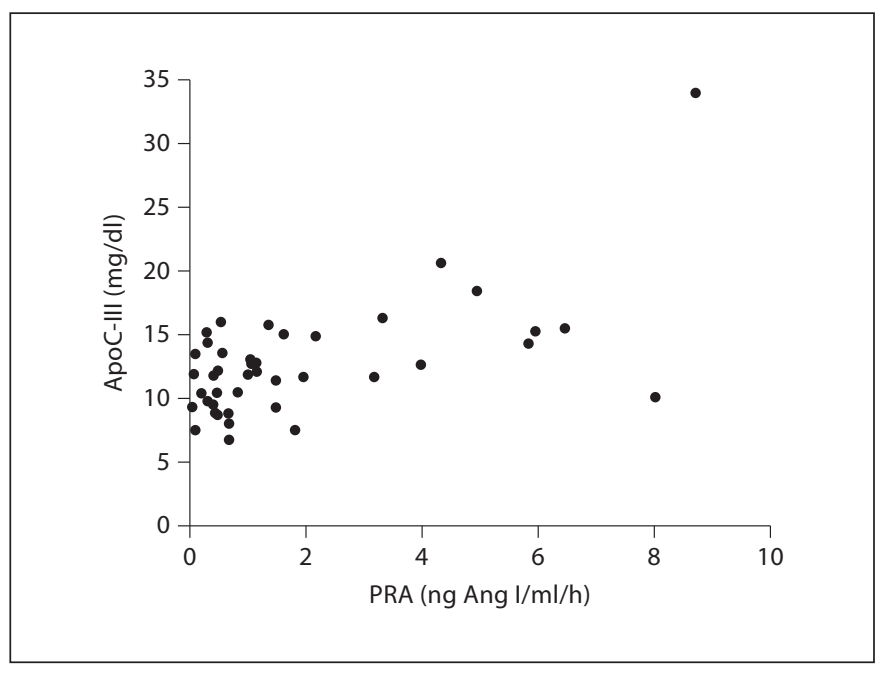

Fig. 2. Correlation between PRA and ApoC-III in patients with atherosclerotic renovascular disease $(n=42)$ at baseline 4 weeks after PTRA. In a multiple regression model (see 'Results'), only PRA was significantly associated with ApoC-III ( $\mathrm{p}<0.001, \mathrm{r}=$ $0.74)$.

cally after exclusion of diabetic patients. These analyses resulted in identical statistical results.

\section{Multiple Regression Analyses in ARVD Patients}

As the most striking findings were increases in ApoCIII and ApoC-III-containing lipoproteins in patients with ARVD, we analyzed which variables were significantly correlated with ApoC-III. Only ASBP, ADBP and PRA were significantly correlated to ApoC-III, and these variables were included in a multiple regression analysis as predictors. In this model only PRA was significantly associated with ApoC-III ( $p<0.001, r=0.74$; fig. 2). Similarly, ASBP, ADBP and PRA were significantly correlated to ApoC-III-HS and when included in a multiple regression model only PRA showed a significant association $(p<0.001)$. In addition, the only variable that was significantly correlated with ApoC-III-HP was PRA ( $\mathrm{p}<$ 0.05). Notably, ApoC-III was not correlated to age, BMI, fasting plasma glucose, serum creatinine, eGFR, UAE, leukocyte count or serum albumin levels.

Effects of Candesartan, ARVD-CAN versus ARVD-C

At the time of randomization, there was no statistically significant difference between the ARVD-CAN and ARVD-C groups in age, gender, the proportion of diabetics or smokers, or in any of the other investigated variables (tables 5, 6). Trough SBP at baseline was $160 \pm 23$ and $156 \pm 21 \mathrm{~mm} \mathrm{Hg}$, and trough DBP $88 \pm 13$ and 82 $\pm 9 \mathrm{~mm} \mathrm{Hg}$, in the ARVD-CAN and ARVD-C groups, respectively.

In the ARVD-CAN group, $\mathrm{ASBP}$ and $\mathrm{ADBP}$ were significantly reduced 11 months after randomization compared to baseline values ( $p<0.05$; table 5$)$; although reductions were not significantly different from those in the ARVD-C group (table 5). ARVD-CAN showed a significantly more pronounced increase in serum creatinine concentration, and reduction in eGFR, compared to ARVD-C $(\mathrm{p}<0.05$; table 5$)$.

Candesartan treatment had no significant effects on ApoC-III or ApoC-III-containing lipoproteins (table 6). In the ARVD-CAN group, there were small but statistically significant reductions in ApoA-I (142 \pm 10 vs. 136 $\pm 13 \mathrm{mg} / \mathrm{dl}$, at baseline and after $11 \mathrm{months}$, respectively, $\mathrm{p}<0.05)$ and LpA-I $(35 \pm 4$ vs. $33 \pm 4 \mathrm{mg} / \mathrm{dl}$, at baseline and after 11 months, respectively, $\mathrm{p}<0.05)$ that were significantly different $(\mathrm{p}<0.05)$ from those in the ARVD-C group in which these variables were unaltered 11 months after randomization (data not shown). There were no statistically significant differences between groups in any of the other investigated variables.

\section{Discussion}

The main finding of the present study was that hypertensive patients with ARVD who had gone through PTRA 4 weeks earlier had increased plasma concentrations of TG, VLDL-C, ApoC-III and ApoC-III-containing lipoproteins compared to healthy controls in spite of ongoing treatment with statins. 
Table 5. Ambulatory blood pressure, kidney function and lipids at baseline and 11 months after randomization

\begin{tabular}{|c|c|c|c|c|c|c|}
\hline & \multicolumn{3}{|c|}{ ARVD-controls $(\mathrm{n}=16)$} & \multicolumn{3}{|c|}{ ARVD-candesartan $(\mathrm{n}=16)$} \\
\hline & baseline & 11 months & $\%$ change & baseline & 11 months & $\%$ change \\
\hline ASBP, $\mathrm{mm} \mathrm{Hg}$ & $134 \pm 11$ & $132 \pm 13$ & $-2 \pm 8$ & $142 \pm 14$ & $132 \pm 13^{\dagger}$ & $-6 \pm 9$ \\
\hline ADBP, mm Hg & $75 \pm 8$ & $74 \pm 7$ & $0 \pm 8$ & $79 \pm 13$ & $76 \pm 12^{\dagger}$ & $-4 \pm 6$ \\
\hline S-creatinine, $\mu \mathrm{mol} / \mathrm{l}$ & $102 \pm 23$ & $119 \pm 88$ & $+14 \pm 69$ & $119 \pm 52$ & $142 \pm 102$ & $+18 \pm 50^{*}$ \\
\hline $\mathrm{eGFR}, \mathrm{ml} / \mathrm{min} / 1.73 \mathrm{~m}^{2}$ & $61 \pm 15$ & $62 \pm 22$ & $0 \pm 26$ & $58 \pm 23$ & $52 \pm 23$ & $-8 \pm 28^{*}$ \\
\hline $\mathrm{TC}, \mathrm{mg} / \mathrm{dl}$ & $163 \pm 23$ & $169 \pm 31$ & $+4 \pm 12$ & $184 \pm 41$ & $186 \pm 45$ & $+1 \pm 10$ \\
\hline HDL-C, mg/dl & $46 \pm 9$ & $50 \pm 7^{\dagger}$ & $+10 \pm 13$ & $47 \pm 12$ & $48 \pm 14$ & $+4 \pm 20$ \\
\hline LDL-C, mg/dl & $89 \pm 23$ & $88 \pm 28$ & $+1 \pm 20$ & $101 \pm 34$ & $102 \pm 40$ & $0 \pm 17$ \\
\hline VLDL-C, mg/dl & $28 \pm 11$ & $26 \pm 10$ & $+4 \pm 48$ & $37 \pm 18$ & $36 \pm 19$ & $+1 \pm 42$ \\
\hline $\mathrm{TG}, \mathrm{mg} / \mathrm{dl}$ & $139 \pm 57$ & $156 \pm 114$ & $+20 \pm 79$ & $183 \pm 88$ & $179 \pm 96$ & $+1 \pm 42$ \\
\hline
\end{tabular}

ASBP = Ambulatory systolic blood pressure during $24 \mathrm{~h}$; ADBP = ambulatory diastolic blood pressure during $24 \mathrm{~h}$; eGFR = estimated glomerular filtration rate; $\mathrm{TC}=$ total cholesterol; HDL-C = high-density lipoprotein-cholesterol; LDL-C = low-density lipoprotein-cholesterol; VLDL-C = very-low-density lipoprotein-cholesterol; TG = triglycerides.

Values are means $\pm \mathrm{SD} .{ }^{\dagger} \mathrm{p}<0.05$ within group effect 11 months vs. baseline; ${ }^{*} \mathrm{p}<0.05$ ARVD-candesartan vs. ARVD-controls.

Table 6. Plasma levels of ApoC-III and ApoC-III-containing lipoproteins at baseline and 11 months after randomization

\begin{tabular}{|c|c|c|c|c|c|c|}
\hline & \multicolumn{3}{|c|}{ ARVD-controls $(\mathrm{n}=16)$} & \multicolumn{3}{|c|}{ ARVD-candesartan $(n=16)$} \\
\hline & baseline & 11 months & $\%$ change & baseline & 11 months & $\%$ change \\
\hline ApoC-III, mg/dl & $11.8 \pm 2.3$ & $12.4 \pm 7.0$ & $+5 \pm 44$ & $12.7 \pm 3.5$ & $12.9 \pm 4.6$ & $+4 \pm 31$ \\
\hline ApoC-III-HS, mg/dl & $8.4 \pm 1.9$ & $7.4 \pm 2.7$ & $-11 \pm 26$ & $9.2 \pm 2.7$ & $8.9 \pm 4.1$ & $-2 \pm 38$ \\
\hline ApoC-III-HP, mg/dl & $3.5 \pm 1.0$ & $4.8 \pm 5.5$ & $+39 \pm 129$ & $3.7 \pm 1.7$ & $4.1 \pm 1.8$ & $+19 \pm 56$ \\
\hline ApoC-III ratio & $2.6 \pm 0.9$ & $2.1 \pm 1.0$ & $-13 \pm 39$ & $2.8 \pm 1.0$ & $2.3 \pm 1.1$ & $-9 \pm 41$ \\
\hline LpB:C, mg/dl & $10.3 \pm 3.8$ & $9.7 \pm 5.4$ & $+4 \pm 63$ & $11.1 \pm 3.7$ & $8.9 \pm 5.2$ & $-19 \pm 34$ \\
\hline LpB:C:E, mg/dl & $12.2 \pm 4.7$ & $12.8 \pm 4.0$ & $+17 \pm 55$ & $16.0 \pm 5.2$ & $14.5 \pm 5.5$ & $-7 \pm 29$ \\
\hline LpA-II:B:C:D:E, mg/dl & $21.1 \pm 6.3$ & $17.8 \pm 9.3$ & $-14 \pm 36$ & $23.3 \pm 11.2$ & $20.7 \pm 14.1$ & $-4 \pm 51$ \\
\hline ApoC-III-containing Lp:s, mg/dl & $44 \pm 12$ & $40 \pm 15$ & $-6 \pm 27$ & $50 \pm 18$ & $44 \pm 20^{\dagger}$ & $-12 \pm 21$ \\
\hline
\end{tabular}

Apo = Apolipoprotein; HS = heparin-manganese supernate; $\mathrm{HP}=$ heparin-manganese precipitate. The ApoC-III ratio was calculated as ApoC-III-HS/ApoC-III-HP. ApoC-III-containing Lp:s were calculated as LpB:C + LpB:C:E + LpA-II:B:C:D:E.

Values are means $\pm \mathrm{SD} .{ }^{\dagger} \mathrm{p}<0.05$ within group effect 11 months vs. baseline. There were no statistically significant differences between groups.

Notably, ARVD patients showed elevated plasma levels of ApoC-III and ApoC-III-containing lipoproteins even though concentrations of TC and LDL-C were significantly reduced most likely as a consequence of ongoing treatment with statins. The ApoC-III-containing lipoproteins that in addition to ApoB also contain ApoCIII have triglycerides as their major lipid constituent and are generally referred to as triglyceride-rich. The lipoprotein abnormalities in ARVD patients show similarities to the renal dyslipidemia described in patients with CKD and reduced GFR that is characterized by increased levels of triglyceride-rich ApoB- and ApoC-containing lipoproteins that typically express ApoC-III $[7,8]$. However, in contrast to patients with CKD in which specifically LpB:C particles are highly increased [22], ARVD patients showed an increase mainly in LpB:C:E. Abnormalities in the spectrum and composition of individual lipoprotein particles in renal dyslipidemia are present in both normolipidemic and hyperlipidemic CKD patients and can be detected already when kidney function is moderately reduced [16, 24]. De Boer et al. [24] detected a significant association between cystatin $\mathrm{C}$ levels and lipoprotein $\mathrm{ab}$ - 
normalities in patients with eGFR $>60 \mathrm{ml} / \mathrm{min} / 1.73 \mathrm{~m}^{2}$. In the present study, eGFR averaged $59 \mathrm{ml} / \mathrm{min} / 1.73 \mathrm{~m}^{2}$ in ARVD patients, and it is possible that reduced GFR could have contributed to dyslipidemia. Still, using multiple regression analysis we could not detect a significant association between eGFR and ApoC-III levels in ARVD patients, suggesting that other mechanisms were also involved. Plasma ApoC-III levels have been shown to be elevated in type 2 diabetic patients [25]. In the present study, only 4 of 42 patients with ARVD had diabetes type 2 and statistical analyses of the data after excluding these patients produced identical results clearly indicating that lipoprotein abnormalities in ARVD patients were not caused by diabetes. Similarly, we did not detect a significant correlation between fasting plasma glucose concentrations and ApoC-III in the present study. This could be explained by the low number of diabetic patients and the fact that glucose levels were within the normal range in the vast majority of patients.

It should be emphasized that all ARVD patients were on statin treatment in the present study and that this could have masked underlying lipoprotein abnormalities. Previous studies have shown that statin treatment effectively reduces cholesterol-rich ApoB-containing lipoproteins including their characteristic lipid and apolipoprotein constituents (TC, LDL-C, ApoB, and ApoE) in CKD patients $[19,22]$ as well as in other patient groups $[26,27]$. However, statins are much less effective in reducing triglyceride-rich ApoB- and ApoC-containing lipoproteins such as LpB:C and LpB:C:E and their constituents VLDL-C, TG, and ApoC-III [19, 22]. Although the present study was not designed to examine the effects of statins on lipoprotein abnormalities, our results are in agreement with earlier findings and suggest that statin treatment does not normalize triglyceride-rich ApoBand ApoC-III-containing lipoproteins in ARVD patients.

To our knowledge, only one previous study by Scoble et al. [4] has specifically investigated lipid abnormalities in ARVD patients, although lipoprotein subclasses were not analyzed. These investigators found markedly reduced ApoA-I levels and as a consequence a lower ApoAI/ApoB ratio in patients with ARAS who were not on lipid-lowering therapy, compared to matched control patients. Notably, in that study controls were matched for renal function and had similar serum creatinine levels as ARAS patients. This may explain why there were no significant differences between groups in TG or HDL levels, which are usually observed in renal dyslipidemia.

Considering that CV disease is the major cause of death in patients with ARVD [2] it is intriguing that lipo- protein abnormalities in ARVD patients on statin treatment in the present study have previously been shown to be atherogenic [28-31]. In the Monitored Atherosclerosis Regression Study (MARS), elevated levels of ApoB- and ApoC-containing triglyceride-rich lipoproteins, and ApoC-III, contributed significantly to the progression of coronary artery disease as evaluated by sequential coronary angiography [29]. In addition, in the Cholesterol And Recurrent Events (CARE) trial increased ApoC-III concentration in VLDL and IDL was a strong predictor of coronary events [30]. Furthermore, recent analyses from the Hoorn study showed that an increased plasma ApoC-III concentration independently was associated with cardiovascular mortality [31]. In the current study, both total ApoC-III and ApoC-III-HP (i.e. ApoC-III in triglyceride-rich VLDL+LDL) were elevated in ARVD patients and these alterations may play a pathophysiological role both in the development of dyslipidemia and in the vascular disease process in these individuals. ApoC-III is a major regulator of lipolysis primarily by inhibiting endothelial-bound lipoprotein lipase, the principal enzyme necessary for the hydrolysis of triglyceride-rich lipoproteins [32]. Thus, the finding of increased ApoC-III levels in the present study may reflect the accumulation of intact and partially metabolized ApoB- and ApoC-containing lipoproteins due to a retarded catabolism of these lipoproteins. In addition, increased ApoC-III per se may promote the development of atherosclerosis by stimulating the activation and adhesion of peripheral monocytes to endothelial cells $[33,34]$ and by impairing endothelial insulin signaling and endothelium-dependent relaxation [35]. A potentially effective therapy in patients with ARVD would be the combination of statins with fibrates, although other combination therapies could also be considered. Fibrates and other peroxisome proliferator-activated receptor (PPAR) agonists have the potential to beneficially affect the catabolism of triglyceride-rich ApoBand ApoC-containing lipoproteins [36]. For instance, Schuster et al. [37] found that tesaglitazar, a dual PPAR alpha/gamma agonist, markedly reduced triglyceriderich lipoproteins in nondiabetic subjects with insulin resistance. However, tesaglitazar was withdrawn from clinical development due to side effects. Thus, although PPAR agonists have the potential to correct dyslipidemia in ARVD, this hypothesis, and the impact on clinical endpoints need to be tested in clinical trials.

In the present study there was a significant association between PRA and ApoC-III levels in ARVD patients, suggesting that an activation of the renin-angiotensin system could increase ApoC-III. Still, treatment with 
candesartan for 11 months did not significantly influence plasma levels of ApoC-III or ApoC-III-containing lipoproteins, indicating that Ang II, via the Ang II type-1 receptor, was not causatively involved. However, the number of randomized patients in the present study was small and larger studies are warranted.

In conclusion, patients with ARVD showed elevated levels of triglyceride-rich ApoC-III-containing lipoproteins and increased ApoC-III in spite of ongoing treatment with statins. These lipoprotein abnormalities, which were not corrected by candesartan treatment, have previously been shown to be atherogenic and may contribute to progressive atherosclerosis in ARVD patients.

\section{Acknowledgements}

This study was supported by grants from the Swedish HeartLung Foundation, the Göteborg Medical Society, the Swedish Medical Society, the Swedish Association for Kidney Patients, the Swedish Society of Nephrology, Brit Wennerström's Research Foundation, AstraZeneca, Mölndal, Sweden, and a grant from the Swedish state under the LUA/ALF agreement. There are no conflicts of interest. We thank Inger Olander and Lotta Sundström for expert technical assistance.

\section{Disclosure Statement}

None of the authors has any conflicts of interest. The results presented in this paper have not been published previously in whole or part, except in abstract form.

\section{References}

1 Johansson M, Herlitz H, Jensen G, Rundqvist B, Friberg P: Increased cardiovascular mortality in hypertensive patients with renal artery stenosis: relation to sympathetic activation, renal function and treatment regimens. J Hypertens 1999; 17:1743-1750.

-2 Wright JR, Shurrab AE, Cheung C, Waldek S, O’Donoghue DJ, Foley RN, Mamtora H, Kalra PA: A prospective study of the determinants of renal functional outcome and mortality in atherosclerotic renovascular disease. Am J Kidney Dis 2002;39:1153-1161.

$\checkmark 3$ Conlon PJ, Little MA, Pieper K, Mark DB: Severity of renal vascular disease predicts mortality in patients undergoing coronary angiography. Kidney Int 2001;60:1490-1497.

4 Scoble JE, de Takats D, Ostermann ME, Connolly JO, Scott NR, Beeso JA, Poyser KH, Peters TJ, Sherwood RA: Lipid profiles in patients with atherosclerotic renal artery stenosis. Nephron 1999;83:117-121.

5 Attman PO, Samuelsson O: Dyslipidemia of kidney disease. Curr Opin Lipidol 2009;20: 293-299.

-6 Alaupovic P: The concept of apolipoproteindefined lipoprotein families and its clinical significance. Curr Atheroscler Rep 2003;5: 459-467.

$\checkmark 7$ Attman PO, Samuelsson O, Alaupovic P: Lipoprotein metabolism and renal failure. Am J Kidney Dis 1993;21:573-592.

$\checkmark 8$ Chan DT, Irish AB, Dogra GK, Watts GF: Dyslipidaemia and cardiorenal disease: mechanisms, therapeutic opportunities and clinical trials. Atherosclerosis 2008;196: 823-834.

$\checkmark 9$ Alaupovic P: Apolipoprotein composition as the basis for classifying plasma lipoproteins: characterization of ApoA- and ApoB-containing lipoprotein families. Prog Lipid Res 1991;30:105-138
10 Ginsberg HN: New perspectives on atherogenesis: role of abnormal triglyceride-rich lipoprotein metabolism. Circulation 2002; 106:2137-2142.

11 Lee SJ, Campos H, Moye LA, Sacks FM: LDL containing apolipoprotein CIII is an independent risk factor for coronary events in diabetic patients. Arterioscler Thromb Vasc Biol 2003;23:853-858.

12 Asztalos BF, Cupples LA, Demissie S, Horvath $\mathrm{KV}$, Cox $\mathrm{CE}$, Batista MC, Schaefer EJ: High-density lipoprotein subpopulation profile and coronary heart disease prevalence in male participants of the Framingham Offspring Study. Arterioscler Thromb Vasc Biol 2004;24:2181-2187.

13 Luc G, Bard JM, Ferrières J, Evans A, Amouyel P, Arveiler D, Fruchart JC, Ducimetière P: Value of HDL cholesterol, apolipoprotein A-I, lipoprotein A-I, and lipoprotein A-I/A-II in prediction of coronary heart disease: the PRIME Study. Prospective Epidemiological Study of Myocardial Infarction. Arterioscler Thromb Vasc Biol 2002;22: 1155-1161.

14 Puchois P, Kandoussi A, Fievet P, Fourrier JL, Bertrand M, Koren E, Fruchart JC: Apolipoprotein A-I containing lipoproteins in coronary artery disease. Atherosclerosis 1987;68:35-40.

15 Attman PO, Alaupovic P: Lipid and apolipoprotein profiles of uremic dyslipoproteinemia - relation to renal function and dialysis. Nephron 1991;57:401-410.

16 Samuelsson O, Attman PO, Knight-Gibson C, Kron B, Larsson R, Mulec H, Weiss L, Alaupovic P: Lipoprotein abnormalities without hyperlipidaemia in moderate renal insufficiency. Nephrol Dial Transplant 1994; 9:1580-1585.
17 Alhadad A, Guron G, Fortuna-Nowakowska E, Saeed A, Mattiasson I, Jensen G, Lindblad B, Gottsäter A, Herlitz H: Renal angioplasty causes a rapid transient increase in inflammatory biomarkers, but reduced levels of interleukin- 6 and endothelin-1 1 month after intervention. J Hypertens 2007;25:19071914.

18 Levey AS, Coresh J, Greene T, Stevens LA, Zhang YL, Hendriksen S, Kusek JW, Van Lente F: Using standardized serum creatinine values in the modification of diet in renal disease study equation for estimating glomerular filtration rate. Ann Intern Med 2006;145:247-254

-19 Samuelsson O, Attman PO, Knight-Gibson C, Mulec H, Weiss L, Alaupovic P: Fluvastatin improves lipid abnormalities in patients with moderate to advanced chronic renal insufficiency. Am J Kidney Dis 2002;39: 67-75.

20 Friedewald WT, Levy RI, Fredrickson DS: Estimation of the concentration of low-density lipoprotein cholesterol in plasma, without use of the preparative ultracentrifuge. Clin Chem 1972;18:499-502.

21 Marz W, Trommlitz M, Gross W: Differential turbidimetric assay for subpopulations of lipoproteins containing apolipoprotein A-I. J Clin Chem Clin Biochem 1988;26:573578.

22 Alaupovic P, Attman PO, Knight-Gibson C, Mulec H, Weiss L, Samuelsson O: Effect of fluvastatin on apolipoprotein-defined lipoprotein subclasses in patients with chronic renal insufficiency. Kidney Int 2006;69: 1865-1871.
Nowakowska Fortuna/Herlitz/Saeed/ Attman/Jensen/Alaupovic/Guron 
-23 Alaupovic P, Hodis HN, Knight-Gibson C, Mack WJ, LaBree L, Cashin-Hemphill L, Corder CN, Kramsch DM, Blankenhorn DH: Effects of lovastatin on ApoA- and ApoB-containing lipoproteins: families in a subpopulation of patients participating in the Monitored Atherosclerosis Regression Study (MARS). Arterioscler Thromb 1994; 14:1906-1913.

-24 de Boer IH, Astor BC, Kramer H, Palmas W, Seliger SL, Shlipak MG, Siscovick DS, Tsai MY, Kestenbaum B: Lipoprotein abnormalities associated with mild impairment of kidney function in the multi-ethnic study of atherosclerosis. Clin J Am Soc Nephrol 2008; 3:125-132.

-25 Hiukka A, Fruchart-Najib J, Leinonen E, Hilden H, Fruchart JC, Taskinen MR: Alterations of lipids and apolipoprotein CIII in very low density lipoprotein subspecies in type 2 diabetes. Diabetologia 2005;48:12071215.

26 Bard JM, Parra HJ, Camare R, et al: A multicenter comparison of the effects of simvastatin and fenofibrate therapy in severe primary hypercholesterolemia, with particular emphasis on lipoproteins defined by their apolipoprotein composition. Metabolism 1992;41:498-503.
27 März W, Scharnagl H, Abletshauser C, Hoffmann MM, Berg A, Keul J, Wieland $\mathrm{H}$, Baumstark MW: Fluvastatin lowers atherogenic dense low-density lipoproteins in postmenopausal women with the atherogenic lipoprotein phenotype. Circulation 2001;103: 1942-1948.

28 Blankenhorn DH, Alaupovic P, Wickham E, Chin HP, Azen SP: Prediction of angiographic change in native human coronary arteries and aortocoronary bypass grafts: lipid and nonlipid factors. Circulation 1990; 81:470-476.

29 Alaupovic P, Mack WJ, Knight-Gibson C, Hodis HN: The role of triglyceride-rich lipoprotein families in the progression of atherosclerotic lesions as determined by sequential coronary angiography from a controlled clinical trial. Arterioscler Thromb Vasc Biol 1997; 17:715-722.

-30 Sacks FM, Alaupovic P, Moye LA, Cole TG, Sussex B, Stampfer MJ, Pfeffer MA, Braunwald E: VLDL, apolipoproteins B, CIII, and $\mathrm{E}$, and risk of recurrent coronary events in the Cholesterol And Recurrent Events (CARE) trial. Circulation 2000;102:18861892.

-31 Scheffer PG, Teerlink T, Dekker JM, Bos G, Nijpels G, Diamant M, Kostense PJ, Stehouwer CD, Heine RJ: Increased plasma apolipoprotein C-III concentration independently predicts cardiovascular mortality: the Hoorn Study. Clin Chem 2008;54:13251330.

-32 Wang CS, McConathy WJ, Kloer HU, Alaupovic P: Modulation of lipoprotein lipase activity by apolipoproteins: effect of apolipoprotein C-III. J Clin Invest 1985;75:384-390.
33 Kawakami A, Aikawa M, Alcaide P, Luscinskas FW, Libby P, Sacks FM: Apolipoprotein CIII induces expression of vascular cell adhesion molecule-1 in vascular endothelial cells and increases adhesion of monocytic cells. Circulation 2006;114:681-687.

34 Kawakami A, Aikawa M, Libby P, Alcaide P, Luscinskas FW, Sacks FM: Apolipoprotein CIII in apolipoprotein B lipoproteins enhances the adhesion of human monocytic cells to endothelial cells. Circulation 2006; 113:691-700.

-35 Kawakami A, Osaka M, Tani M, Azuma H, Sacks FM, Shimokado K, Yoshida M: Apolipoprotein CIII links hyperlipidemia with vascular endothelial cell dysfunction. Circulation 2008;118:731-742.

36 Barter PJ, Rye KA: Is there a role for fibrates in the management of dyslipidemia in the metabolic syndrome? Arterioscler Thromb Vasc Biol 2008;28:39-46.

37 Schuster H, Fagerberg B, Edwards S, Halmos T, Lopatynski J, Stender S, Birketvedt GS, Tonstad S, Gause-Nilsson I, Halldórsdóttir S, Ohman KP, SIR Investigators: Tesaglitazar, a dual peroxisome proliferator-activated receptor alpha/gamma agonist, improves apolipoprotein levels in non-diabetic subjects with insulin resistance. Atherosclerosis 2008;197:355-362. 